\title{
Urate Transporter Gene SLC22A12 Polymorphisms Associated with Obesity and Metabolic Syndrome in Caucasians with Hypertension
}

\author{
Mohamed Shafiu ${ }^{a, b}$ Richard J. Johnson ${ }^{b, c}$ Stephen T. Turner ${ }^{d}$ Taimour Langaee $^{a}$ \\ Yan Gong ${ }^{\text {a }}$ Arlene B. Chapman ${ }^{\mathrm{e}}$ John G. Gums ${ }^{\mathrm{a}, \mathrm{b}}$ Julie A. Johnson a, b \\ ${ }^{a}$ College of Pharmacy and Center for Pharmacogenomics and b ${ }^{b}$ College of Medicine, University of Florida, Gainesville, \\ Fla., 'Division of Renal Diseases and Hypertension, University of Colorado, Denver, Colo., 'Division of Nephrology and \\ Hypertension, Department of Medicine, Mayo Clinic, Rochester, Minn., and e Division of Nephrology, Emory University \\ School of Medicine, Atlanta, Ga., USA
}

\section{Key Words}

Hypertension · Metabolic syndrome • Obesity $\cdot$ SLC22A12

polymorphisms · URAT1 • Uric acid

\begin{abstract}
Background/Aims: Hyperuricemia is associated with obesity and the metabolic syndrome. URAT1 is a urate transporter, and we tested the association of URAT1 transporter gene (SLC22A12) polymorphisms with obesity and the metabolic syndrome in hypertensive subjects. Methods: Patients with essential hypertension ( $n=414$ ) from a randomized controlled study were genotyped for SLC22A12 SNPs rs11602903, rs505802 and rs11231825. Results: In Caucasians, SLC22A12 SNPs were associated with the body mass index (BMI). rs11602903 was associated with BMI ( $p<0.0001)$, waist circumference $(p=0.003)$, HDL cholesterol $(p=0.018)$ and the metabolic syndrome ( $p=0.033)$, and accounted for $7 \%$ of the variation of BMI in Caucasians. In African Americans, SLC22A12 SNP rs11602903 was not associated with BMI, waist circumference, HDL cholesterol or triglycerides. Conclusion: The URAT1 gene SLC22A12 polymorphism may play a role in obesity and the metabolic syndrome in Caucasian hypertensive subjects.

Copyright $\odot 2012$ S. Karger AG, Basel
\end{abstract}

\section{Introduction}

An elevated serum uric acid is commonly associated with the metabolic syndrome [1-3], hypertension [4], and cardiovascular disease $[5,6]$. While the increase in serum uric acid was often considered secondary to these conditions [7-9], recent studies suggest it may have a contributory role [10]. First, serum uric acid commonly precedes and independently predicts hypertension $[11,12]$, insulin resistance/diabetes [13, 14], and obesity [15], which is inconsistent with it solely being a secondary factor. Second, studies in cell culture and animal models have suggested a causal role of uric acid in models of the metabolic syndrome and hypertension [16, 17]. Third, recent clinical trials, primarily pilot in nature, found potential benefits of lowering uric acid on blood pressure and insulin resistance [18-20]. These studies have renewed interest in uric acid as a potential mediator in the current epidemic of obesity and cardiovascular disease.

Few studies have examined whether polymorphisms affecting urate transport can predict features of the metabolic syndrome. Polymorphisms in the uric acid transporter $S L C 2 A 9$ are associated with elevated serum uric acid and risk for gout $[21,22]$, but $S L C 2 A 9$ polymorphisms

\section{KARGER \\ Fax +4161306 1234 \\ E-Mail karger@karger.ch}

www.karger.com
(C) 2012 S. Karger AG, Basel

1420-4096/12/0356-0477\$38.00/0

Accessible online at:

www.karger.com/kbr
Dr. Mohamed Shafiu

Renal Associates, P.A

16620 US Hwy $281 \mathrm{~N}$ \# 300

San Antonio, TX 78232 (USA)

Tel. +1 210614 1231, E-Mail mshafiu@ rapadocs.com 
are not associated with obesity and metabolic phenotypes [22]. However, whereas gout is a disease driven by extracellular concentrations of uric acid, the metabolic effects of uric acid are driven by its intracellular concentrations $[23,24]$, and SLC2A9 exports uric acid out of cells $[25,26]$.

In contrast to SLC2A9, the transporter URAT1 mediates entry of uric acid into cells [27]. Sautin et al. [24] reported that the URAT1 transporter is located on adipocytes where it drives inflammation and oxidative stress in response to uric acid. Adipocytes may also produce uric acid via intracellular xanthine oxidoreductase (XOR) [28]. A key role for XOR has been shown in adipogenesis, and XOR knockout mice fail to get fat [28].

These studies raise the possibility that urate transport into adipocytes may have a role in obesity and the metabolic syndrome. As such, we hypothesized that polymorphisms in the URAT1 transporter gene SLC22A12 may be associated with obesity and the metabolic syndrome.

\section{Methods}

\section{Study Population}

The Pharmacogenomic Evaluation of Antihypertensive Responses (PEAR) study (NCT00246519) is an ongoing prospective randomized parallel group study undertaken primarily to investigate genetic determinants to the antihypertensive and adverse metabolic effects of a thiazide diuretic and atenolol in mild-tomoderate primary hypertensive patients aged between 17 and 65 years without a history of diabetes mellitus or heart disease [29]. Subjects with elevated creatinine (males with creatinine $>1.5$ and females with creatinine $>1.4$ ), secondary hypertension, history of gout, alcohol/drug abuse or elevated liver function tests (elevated AST or ALT) were excluded. Randomized patients had all antihypertensives discontinued for an average of 1 month after which baseline studies were conducted. Patients were then randomized to treatment with either atenolol or hydrochlorothiazide. The initial 414 randomized patients were selected for this study after approval from the PEAR steering committee. Institutional review boards at the sites where PEAR was conducted, including the University of Florida, Gainesville, Fla., the Mayo Clinic, Rochester, Minn., and Emory University School of Medicine, Atlanta, Ga., all approved the PEAR study protocol, and all study participants provided informed written consent.

\section{Phenotypes Studied}

PEAR involved the collection of baseline data in all patients in the untreated state. Those who were treated with antihypertensives on entry to the study had them discontinued, with a washout period that was a minimum of 18 days, and typically 4-6 weeks in duration. Baseline data were collected at the end of this washout period and prior to initiation of the study drug. All data for this analysis arise from the baseline untreated study period in the PEAR study before addition of atenolol or hydrochlorothiazide. Waist circumference was measured to the nearest $0.5 \mathrm{~cm}$. Weight and height were measured to the nearest $0.1 \mathrm{~kg}$ and $0.5 \mathrm{~cm}$, respec- tively. Baseline laboratory studies including blood urea, serum creatinine, serum uric acid, and fasting lipids were measured on a Hitachi 911 Chemistry analyzer at the Mayo Clinic.

\section{Genotyping}

We selected promoter SNPs rs11602903 and rs505802 primarily to evaluate a likely functional SNP of the SLC22A12 gene that may be in linkage disequilibrium (LD) with an SNP reported in association studies with serum uric acid and gout (rs11231825) [30, 31]. The SNP rs11602903 in the promoter region was previously reported to be associated with reduced fractional excretion of uric acid $\left(\mathrm{FE}_{\mathrm{UA}}\right)$, which is defined as $\left[\mathrm{U}_{\mathrm{UA}} \times \mathrm{S}_{\mathrm{Cr}}\right] /\left[\mathrm{S}_{\mathrm{UA}} \times \mathrm{U}_{\mathrm{Cr}}\right] \times 100$, where $U_{U A}$ and $U_{C r}$ are the urinary concentrations of uric acid and creatinine and $\mathrm{S}_{\mathrm{UA}}$ and $\mathrm{S}_{\mathrm{Cr}}$ reflect the respective serum concentrations [30]. SNP rs505802 is in complete LD $\left(r^{2}=1\right.$ in Caucasians) with SNP rs11231825. Based on the lowest minor allele frequency (MAF) of 0.15 , we estimated that about 250 study subjects would provide a power of $80 \%$ to detect the baseline difference in uric acid of $0.4 \mathrm{SD}(0.42-0.5 \mathrm{mg} / \mathrm{dl}$ of uric acid) with an $\alpha$ value of 0.05 . We presumed that a significant difference in uric acid by genotype may be enough to detect a genotype association with obesity and the metabolic syndrome. Genomic DNA isolated from peripheral lymphocytes was used for genotyping. Genotype determination was carried out by the ABI TaqMan Prism 7900HT sequence detection system (Applied Biosystems) for rs505802 and rs11231825. The SNP rs11602903 was genotyped by pyrosequencing. The following PCR and sequencing primers were used for pyrosequencing: forward primer 5'-ATTGGGCACACCGAACCTG-3', reverse primer 5'-TGCTGTGGTTGGCGTCCT-3', and sequencing primer 5'-GAAGCTCCACCGAGG-3'. For quality control, $10-15 \%$ of samples were genotyped twice. All genotypes were in concordance on repeat analysis.

\section{Statistical Analysis}

The Hardy-Weinberg equilibrium (HWE) was tested by using the $\chi^{2}$ test. To reduce kurtosis of the distribution, we square root transformed serum uric acid. Due to usual statistical genetic procedures, and particularly because of the differences in uric acid and MAF by race, all analyses were conducted separately in Caucasians and African Americans. The association of baseline serum uric acid with each of the three SNPS (rs505802, rs11602903, and rs11231825) was done by using analysis of covariance (ANCOVA) tested separately by race. An additive genetic model for the SNPs was used by assigning codes of 0,1 , and 2 for the wildtype homozygotes, heterozygotes, and variant homozygotes, respectively, for each SNP. We used age, gender, and body mass index (BMI) as covariates in association analysis with uric acid. ANCOVA was used for the association analysis of BMI, waist circumference, HDL cholesterol, and serum triglycerides after adjustment for age and gender. The criteria used to diagnose the metabolic syndrome were from the revised Adult Treatment Panel of the National Cholesterol Education Program [32]. We used logistic regression to evaluate the association of SLC22A12 SNPs with the metabolic syndrome after adjusting for age and gender in the model. All analyses were performed using SAS 9.1. Although three SNPs were tested, it turned out they were all in nearly perfect LD, thus the analyses were really essentially the same in Caucasians. Thus no correction was made for testing multiple SNPs. However, because we tested 5 different phenotypes, we defined $\mathrm{p}<0.01$ as statistically significant. 


\section{Results}

Out of 414 subjects from PEAR, 234 Caucasians and 166 African Americans were included in the analysis. We excluded 14 other subjects who were of different ethnicities. Table 1 shows the MAF of SLC22A12 SNPs rs11602903, rs505802, and rs11231825 in Caucasians and African Americans. Each of the minor alleles of the three SLC22A12 SNPs in Caucasians were observed to be the major alleles in African Americans. All analyzed SNPs in each race were in HWE ( $\mathrm{p} \geq 0.05$ ). LD between the three SNPs is shown in figure 1. This reveals that in Caucasians, the three SNPs were in nearly perfect LD, with lower levels of LD among African Americans. Because of the nearly complete LD in Caucasians, we report only the data for promoter SNP rs11602903 since the data for the other two are nearly identical.

Mean serum uric acid $( \pm S D)$ was $5.66 \pm 1.35 \mathrm{mg} / \mathrm{dl}$ in Caucasians and $5.38 \pm 1.45 \mathrm{mg} / \mathrm{dl}$ in African Americans. In Caucasians, rs11602903 was not significantly associated with serum uric acid level (ANCOVA $p=0.15$; table 2). The difference in serum uric acid between $A / A$ versus $\mathrm{T} / \mathrm{T}$ showed a trend toward significance with lower uric acid with increasing copies of the $\mathrm{T}$ allele $(\mathrm{p}=$ 0.0625 after adjustment for age and gender). For African Americans, the relationship of serum uric acid with SNP rs11602903 genotypes showed no differences between groups $(\mathrm{A} / \mathrm{A}, 5.81 \pm 0.12 ; \mathrm{A} / \mathrm{T}, 5.60 \pm 0.22$, and $\mathrm{T} / \mathrm{T}$, $5.37 \pm 0.47 \mathrm{mg} / \mathrm{dl}, \mathrm{p}=0.85)$.

In Caucasians, rs11602903 was highly significantly associated with BMI $(\mathrm{p}<0.0001$, table 2$)$ and waist circumference ( $p=0.003$, table 2). SNP rs11602903 explained 7\% of the variation in BMI in Caucasians. In addition, SNP rs11602903 was significantly associated with HDL cholesterol ( $\mathrm{p}=0.018$, table 2 ) but not with serum triglycerides although there was a trend towards significance (A/A vs. $\mathrm{T} / \mathrm{T}, \mathrm{p}=0.09$, table 2 ). As a replication cohort, we selected the Hypertension Genes Study involving 189 Caucasians with essential hypertension. There was no significant association between SLC22A12 SNP rs11602903 and BMI in this cohort. In African Americans, SLC22A12 SNP rs11602903 was not associated with BMI, waist circumference, HDL cholesterol or triglycerides, nor were the other two SNPs analyzed in this study.

SNP rs11602903 was significantly associated with the metabolic syndrome in Caucasians by logistic regression analysis (table 3). Patients with the AA genotype had 2.5 times odds of having the metabolic syndrome compared to those with the TT genotypes (odds ratio, OR: 2.53, 95\% confidence interval, CI: $1.03-6.22, \mathrm{p}=0.033)$. In contrast,

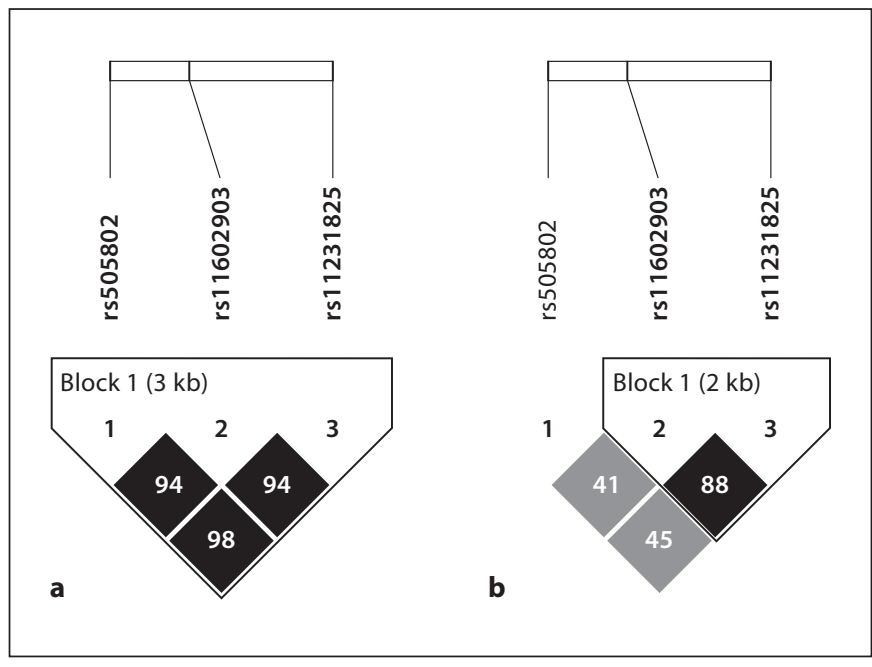

Fig. 1. LD in Caucasians (a) and African Americans (b) for the three SLC22A12 SNPs rs11602903, rs505802, and rs11231825 are shown as $\mathrm{r}^{2}$.

Table 1. MAF and HWE for SLC22A12 polymorphisms in Caucasians and African Americans

\begin{tabular}{|c|c|c|c|c|c|c|}
\hline \multirow[t]{2}{*}{ SLC22A12 } & \multicolumn{3}{|c|}{ Caucasians } & \multicolumn{3}{|c|}{ African Americans } \\
\hline & $\begin{array}{l}\text { minor } \\
\text { allele }\end{array}$ & MAF & $\begin{array}{l}\text { HWE } \\
\text { p value }\end{array}$ & $\begin{array}{l}\text { minor } \\
\text { allele }\end{array}$ & MAF & $\begin{array}{l}\text { HWE } \\
\text { p value }\end{array}$ \\
\hline rs505802 & G & 0.318 & 0.197 & A & 0.274 & 0.152 \\
\hline rs11602903 & A & 0.322 & 0.276 & $\mathrm{~T}$ & 0.156 & 0.854 \\
\hline rs11231825 & $\mathrm{T}$ & 0.325 & 0.129 & $\mathrm{C}$ & 0.154 & 0.219 \\
\hline
\end{tabular}

no association was observed in African Americans, with an OR of 1.27 (0.23-7.07), p = 0.81, for AA, and an OR of $1.28(0.21-7.72), \mathrm{p}=0.82$, for AT, compared to TT individuals.

\section{Discussion}

Our primary finding is that the URAT1 gene $S L$ C22A12 SNP rs11602903 in the promoter region was highly associated with BMI $(\mathrm{p}<0.0001)$ and explained $7 \%$ of the variation in BMI in hypertensive Caucasians from the PEAR study. rs11602903 was also associated with increased waist circumference, lower HDL and the metabolic syndrome in Caucasians. The observation of the association of SNPs in URAT1 with obesity, increased waist circumference, low HDL cholesterol, and 
Table 2. Associations of SLC22A12 SNP rs11602903 with BMI, waist circumference and HDL cholesterol

\begin{tabular}{lcccc}
\hline & $\mathrm{A} / \mathrm{A}$ & $\mathrm{A} / \mathrm{T}$ & $\mathrm{T} / \mathrm{T}$ & $\mathrm{p}$ value \\
\hline Caucasians $(n=234)$ & $\mathrm{n}=28$ & $\mathrm{n}=95$ & $\mathrm{n}=111$ & \\
Age, years & $52.60 \pm 1.67$ & $52.04 \pm 0.98$ & $50.68 \pm 0.82$ & 0.44 \\
Women, \% & 53.57 & 52.17 & 41.44 & 0.26 \\
Serum uric acid, mg/dl & $5.91 \pm 0.21$ & $5.64 \pm 0.11$ & $5.46 \pm 0.10$ & 0.15 \\
Triglycerides, mg/dl & $168.54 \pm 18.16$ & $152.04 \pm 10.02$ & $134.12 \pm 9.19$ & 0.17 \\
HDL cholesterol, mg/dl & $41.97 \pm 2.44$ & $48.83 \pm 1.34$ & $49.78 \pm 1.23$ & 0.018 \\
BMI & $34.93 \pm 1.01$ & $30.27 \pm 0.55$ & $30.51 \pm 0.51$ & $<0.0001$ \\
Waist circumference, cm & $105.63 \pm 2.28$ & $97.22 \pm 1.24$ & $98.39 \pm 1.14$ & 0.0033 \\
\hline African Americans $(n=166)$ & $\mathrm{n}=121$ & $\mathrm{n}=38$ & $\mathrm{n}=7$ & \\
Age, years & $48.55 \pm 7.89$ & $48.0 \pm 8.65$ & $49.0 \pm 11.46$ & 0.92 \\
Women, \% & 66.94 & 84.21 & 85.71 & 0.084 \\
Serum uric acid, mg/dl & $5.8 \pm 0.12$ & $5.6 \pm 0.22$ & $5.37 \pm 0.47$ & 0.85 \\
Triglycerides, mg/dl & $108.75 \pm 8.16$ & $107.83 \pm 14.75$ & $100.7 \pm 32.2$ & 0.97 \\
HDL cholesterol, mg/dl & $49.44 \pm 1.36$ & $50.86 \pm 2.46$ & $51.25 \pm 5.43$ & 0.84 \\
BMI & $31.23 \pm 0.55$ & $31.41 \pm 0.98$ & $30.82 \pm 0.51$ & 0.97 \\
Waist circumference, cm & $96.10 \pm 1.29$ & $99.10 \pm 2.32$ & $99.07 \pm 5.35$ & 0.4888 \\
\hline
\end{tabular}

Data are expressed as means $\pm \mathrm{SD}$.

Table 3. Association of SLC22A12 SNP rs11602903 with the metabolic syndrome in Caucasians by logistic regression

\begin{tabular}{llll}
\hline Variable & OR & $95 \%$ CI & p value \\
\hline Age & 0.96 & $0.93-0.99$ & 0.01 \\
Female gender & 1.57 & $0.92-2.67$ & 0.097 \\
rs11602903 AA genotype & 2.53 & $1.03-6.22$ & 0.033 \\
rs11602903 AT genotype & 0.99 & $0.56-1.74$ & 0.12 \\
\hline
\end{tabular}

the metabolic syndrome is consistent with epidemiological $[13,33]$ and experimental studies $[17,34]$ suggesting a contributory role of uric acid to the pathogenesis of the metabolic syndrome. An elevated uric acid was shown to be an independent risk factor for obesity in a study in Japan [15], and a meta-analysis also found uric acid to independently predict insulin resistance and diabetes [13].

Interestingly, the SLC22A12 SNP rs11602903 correlated with serum uric acid levels in Caucasians in this study, although it did not reach significance. In a case-control study involving Caucasians, Graessler et al. [30] reported that the A/A genotype of SLC22A12 SNP rs11602903 was associated with reduced renal uric acid excretion (OR: 1.8, 95\% CI: $1.129-2.993, \mathrm{p}=0.0139$ for $\left.\mathrm{FE}_{\mathrm{UA}} \leq 6.5 \%\right)$. A decreased renal uric acid excretion implies increased
URAT1 activity which should correlate with higher intracellular uric acid levels.

In contrast to the findings in Caucasians, no relationship of rs11602903 with obesity and the metabolic syndrome was observed in African Americans. Since rs11602903 is not considered a functional SNP, this could be explained by LD differences between both groups. Other explanations are possible. For example, African Americans have a diet that is much higher in sugar [35], and the fructose component in sugar is known to raise intracellular uric acid [36], which could theoretically reduce the impact of a polymorphism involved in urate transport into the cell.

Limitations in this study include our inability to reproduce these findings in a different cohort (The Hypertension Genes Study) involving 189 Caucasians with a similar hypertensive phenotype. This could have been due to the small sample size, sampling error, dietary differences, or differences in genetic factors affecting obesity in that cohort. The weight and height in the hypertension cohort were self-reported so there may be errors in the reported weight by individuals. Despite the limitations, this study raises important questions as to whether transporters regulating intracellular uric acid are involved in the human obesity epidemic.

In conclusion, our data suggest that urate transport SLC22A12 gene polymorphisms may influence obesity 
and the metabolic syndrome in essential hypertension. We hope these studies will stimulate additional research studies investigating the role of genes involved in uric acid metabolism and transport in the pathogenesis of obesity and the metabolic syndrome.

\section{Acknowledgments}

The PEAR study, and this research, is supported by a grant from the National Institutes of Health (Bethesda, Md., USA), grant U01 GM074492, funded as part of the Pharmacogenetics
Research Network. The study was also supported by PEAR CTSA grants UL1-RR092890 (University of Florida), UL1-RR025008 (Emory University), and UL1-RR024150 (Mayo Clinic), and funds from the Mayo Foundation, NIH HL-68607 and an Amgen fellowship grant to Dr. Shafiu.

\section{Disclosure Statement}

Dr. Richard Johnson has patent applications related to lowering uric acid as a means for reducing the metabolic syndrome via the University of Florida. All other authors have no conflicts of interest.

\section{References}

1 Lee J, Sparrow D, Vokonas PS, Landsberg L, Weiss ST: Uric acid and coronary heart disease risk: evidence for a role of uric acid in the obesity-insulin resistance syndrome. The normative aging study. Am J Epidemiol 1995;142:288-294.

-2 Bonora E, Targher G, Zenere MB, Saggiani F, Cacciatori V, Tosi F, Travia D, Zenti MG, Branzi P, Santi L, Muggeo M: Relationship of uric acid concentration to cardiovascular risk factors in young men. Role of obesity and central fat distribution. The Verona Young Men Atherosclerosis Risk Factors Study. Int J Obes Relat Metab Disord 1996; 20:975-980.

-3 TsouliSG, Liberopoulos EN, Mikhailidis DP Athyros VG, Elisaf MS: Elevated serum uric acid levels in metabolic syndrome: an active component or an innocent bystander? Metabolism 2006;55:1293-1301.

-4 Cannon PJ, Stason WB, Demartini FE, Sommers SC, Laragh JH: Hyperuricemia in primary and renal hypertension. $\mathrm{N}$ Engl J Med 1966;275:457-464.

5 Gertler MM, Garn SM, Levine SA: Serum uric acid in relation to age and physique in health and in coronary heart disease. Ann Intern Med 1951;34:1421-1431.

6 Breckenridge A: Hypertension and hyperuricaemia. Lancet 1966;i:15-18.

7 Culleton BF, Larson MG, Kannel WB, Levy D: Serum uric acid and risk for cardiovascular disease and death: the Framingham Heart Study. Ann Intern Med 1999;131:7-13.

8 Vaccarino V, Krumholz HM: Risk factors for cardiovascular disease: one down, many more to evaluate. Ann Intern Med 1999;131: 62-63.

>9 Wannamethee SG, Shaper AG, Whincup $\mathrm{PH}$ : Serum urate and the risk of major coronary heart disease events. Heart 1997;78: 147-153.

10 Feig DI, Kang DH, Johnson RJ: Uric acid and cardiovascular risk. N Engl J Med 2008;359: 1811-1821.
11 Sundstrom J, Sullivan L, D’Agostino RB, Levy D, Kannel WB, Vasan RS: Relations of serum uric acid to longitudinal blood pressure tracking and hypertension incidence. Hypertension 2005;45:28-33.

12 Perlstein TS, Gumieniak O, Williams GH, Sparrow D, Vokonas PS, Gaziano M, Weiss ST, Litonjua AA: Uric acid and the development of hypertension: The normative aging study. Hypertension 2006;48:1031-1036.

13 Kodama S, Saito K, Yachi Y, Asumi M, Sugawara A, Totsuka K, Saito A, Sone H: Association between serum uric acid and development of type 2 diabetes. Diabetes Care 2009; 32:1737-1742.

14 Dehghan A, van Hoek M, Sijbrands EJ, Hofman A, Witteman JC: High serum uric acid as a novel risk factor for type 2 diabetes. Diabetes Care 2008;31:361-362.

-15 Masuo K, Kawaguchi H, Mikami H, Ogihara T, Tuck ML: Serum uric acid and plasma norepinephrine concentrations predict subsequent weight gain and blood pressure elevation. Hypertension 2003;42:474-480.

16 Mazzali M, Hughes J, Kim YG, Jefferson JA, Kang DH, Gordon KL, Lan HY, Kivlighn S, Johnson RJ: Elevated uric acid increases blood pressure in the rat by a novel crystal-independent mechanism. Hypertension 2001;38:1101-1106.

17 Nakagawa T, Hu H, Zharikov S, Tuttle KR, Short RA, Glushakova O, Ouyang X, Feig DI, Block ER, Herrera-Acosta J, Patel JM, Johnson RJ: A causal role for uric acid in fructoseinduced metabolic syndrome. Am J Physiol Renal Physiol 2006;290:F625-F631.

18 Kanbay M, Ozkara A, Selcoki Y, Isik B, Turgut F, Bavbek N, Uz E, Akcay A, Yigitoglu R, Covic A: Effect of treatment of hyperuricemia with allopurinol on blood pressure, creatinine clearance, and proteinuria in patients with normal renal functions. Int Urol Nephrol 2007;39:1227-1233.
19 Feig DI, Soletsky B, Johnson RJ: Effect of allopurinol on blood pressure of adolescents with newly diagnosed essential hypertension: a randomized trial. JAMA 2008;300: 924-932.

20 Ogino K, Kato M, Furuse Y, Kinugasa Y, Ishida K, Osaki S, Kinugawa T, Igawa O, Hisatome I, Shigemasa C, Anker SD, Doehner W: Uric acid-lowering treatment with benzbromarone in patients with heart failure: a double-blind placebo-controlled crossover preliminary study. Circ Heart Fail 2010;3:73-81.

-21 Caulfield MJ, Munroe PB, O’Neill D, Witkowska K, Charchar FJ, Doblado M, Evans S, Eyheramendy S, Onipinla A, Howard P, Shaw-Hawkins S, Dobson RJ, Wallace C, Newhouse SJ, Brown M, Connell JM, Dominiczak A, Farrall M, Lathrop GM, Samani NJ, Kumari M, Marmot M, Brunner E, Chambers J, Elliott P, Kooner J, Laan M, Org E, Veldre G, Viigimaa M, Cappuccio FP, Ji C, Iacone R, Strazzullo P, Moley KH, Cheeseman C: SLC2A9 is a high-capacity urate transporter in humans. PLoS Med 2008;5:e197.

22 Vitart V, Rudan I, Hayward C, Gray NK, Floyd J, Palmer CN, Knott SA, Kolcic I, Polasek O, Graessler J, Wilson JF, Marinaki A, Riches PL, Shu X, Janicijevic B, Smolej-Narancic N, Gorgoni B, Morgan J, Campbell S, Biloglav Z, Barac-Lauc L, Pericic M, Klaric IM, Zgaga L, Skaric-Juric T, Wild SH, Richardson WA, Hohenstein $\mathrm{P}$, Kimber $\mathrm{CH}$, Tenesa A, Donnelly LA, Fairbanks LD, Aringer M, McKeigue PM, Ralston SH, Morris AD, Rudan P, Hastie ND, Campbell H, Wright AF: SLC2A9 is a newly identified urate transporter influencing serum urate concentration, urate excretion and gout. Nat Genet 2008;40:437-442.

-23 Cirillo P, Gersch MS, Mu W, Scherer PM Kim KM, Gesualdo L, Henderson GN, Johnson RJ, Sautin YY: Ketohexokinase-dependent metabolism of fructose induces proinflammatory mediators in proximal tubular cells. J Am Soc Nephrol 2009;20:545-553. 
24 Sautin YY, Nakagawa T, Zharikov S, Johnson RJ: Adverse effects of the classic antioxidant uric acid in adipocytes: NADPH oxidasemediated oxidative/nitrosative stress. Am J Physiol Cell Physiol 2007;293:C584-C596.

25 Bibert S, Hess SK, Firsov D, Thorens B, Geering $\mathrm{K}$, Horisberger JD, Bonny O: Mouse GLUT9: evidences for a urate uniporter. Am J Physiol Renal Physiol 2009;297:F612-F619.

26 Anzai N, Ichida K, Jutabha P, Kimura T, Babu E, Jin CJ, Srivastava S, Kitamura K, Hisatome I, Endou H, Sakurai H: Plasma urate level is directly regulated by a voltage-driven urate efflux transporter URATv1 (SLC2A9) in humans. J Biol Chem 2008;283:2683426838.

-27 Price KL, Sautin YY, Long DA, Zhang L, Miyazaki $\mathrm{H}, \mathrm{Mu} \mathrm{W}$, Endou $\mathrm{H}$, Johnson RJ: $\mathrm{Hu}-$ man vascular smooth muscle cells express a urate transporter. J Am Soc Nephrol 2006;17: 1791-1795.
28 Cheung KJ, Tzameli I, Pissios P, Rovira I, Gavrilova O, Ohtsubo T, Chen Z, Finkel T, Flier JS, Friedman JM: Xanthine oxidoreductase is a regulator of adipogenesis and PPAR $\gamma$ activity. Cell Metab 2007;5:115-128.

29 Johnson JA, Boerwinkle E, Zineh I, Chapman AB, Bailey K, Cooper-DeHoff RM, Gums J, Curry RW, Gong Y, Beitelshees AL, Schwartz G, Turner ST: Pharmacogenomics of antihypertensive drugs: rationale and design of the pharmacogenomic evaluation of antihypertensive responses (PEAR) study. Am Heart J 2009;157:442-449.

30 Graessler J, Graessler A, Unger S, Kopprasch $S$, Tausche AK, Kuhlisch E, Schroeder HE: Association of the human urate transporter 1 with reduced renal uric acid excretion and hyperuricemia in a German Caucasian population. Arthritis Rheum 2006;54:292-300.

31 Shima Y, Teruya K, Ohta H: Association between intronic SNP in urate-anion exchanger gene, SLC22A12, and serum uric acid levels in Japanese. Life Sci 2006;79:2234-2237.
2 Third Report of the National Cholesterol Education Program (NCEP) Expert Panel on Detection, Evaluation, and Treatment of High Blood Cholesterol in Adults (Adult Treatment Panel III) final report. Circulation 2002;106:3143-3421.

33 Johnson RJ, Perez-Pozo SE, Sautin YY, Manitius J, Sanchez-Lozada LG, Feig DI, Shafiu M, Segal M, Glassock RJ, Shimada M, Roncal C, Nakagawa T: Hypothesis: could excessive fructose intake and uric acid cause type 2 diabetes? Endocr Rev 2009;30:96-116.

-34 Reungjui S, Roncal CA, Mu W, Srinivas TR, Sirivongs D, Johnson RJ, Nakagawa T: Thiazide diuretics exacerbate fructose-induced metabolic syndrome. J Am Soc Nephrol 2007; 18:2724-2731.

35 Jalal DI, Smits G, Johnson RJ, Chonchol M: Increased fructose associates with elevated blood pressure. J Am Soc Nephrol 2010;21: 1543-1549.

36 Hallfrisch J: Metabolic effects of dietary fructose. FASEB J 1990;4:2652-2660. 